Article

\title{
Highly Active and Selective Supported Rhenium Catalysts for Aerobic Oxidation of $n$-Hexane and $n$-Heptane
}

\author{
Gopal S. Mishra ${ }^{1,2} \mathbb{E}^{\mathbb{D}}$, Elisabete C. B. A. Alegria ${ }^{1,3, *} \mathbb{1}$, Armando J. L. Pombeiro ${ }^{1}$ and \\ Luísa M. D. R. S. Martins ${ }^{1, *(1)}$ \\ 1 Centro de Química Estrutural, Departamento de Engenharia Química, Instituto Superior Técnico, \\ Universidade de Lisboa, Av. Rovisco Pais, 1049-001 Lisboa, Portugal; mishrags@gmail.com (G.S.M.); \\ pombeiro@tecnico.ulisboa.pt (A.J.L.P.) \\ 2 Materials Laboratory, Chemistry Centre, CQ-VR, University of Trás-os-Montes e Alto Douro (UTAD), \\ 5001-801 Vila Real, Portugal \\ 3 ADEQ, Instituto Superior de Engenharia de Lisboa, Instituto Politécnico de Lisboa, 1959-007 Lisboa, Portugal \\ * Correspondence: ebastos@deq.isel.ipl.pt (E.C.B.A.A.); \\ luisamargaridamartins@tecnico.ulisboa.pt (L.M.D.R.S.M.); Tel.: +351-218-419-264 (L.M.D.R.S.M.)
}

Received: 23 December 2017; Accepted: 13 March 2018; Published: 15 March 2018

\begin{abstract}
A series of derivative C-scorpionate rhenium complexes, i.e., $\left[\operatorname{ReCl}_{2}\left\{\mathrm{NNC}(\mathrm{O}) \mathrm{C}_{6} \mathrm{H}_{5}\right\}\right.$ $\left.(\mathrm{Hpz})\left(\mathrm{PPh}_{3}\right)_{2}\right]$ (A) (where $\mathrm{Hpz}$ is pyrazole), $\left[\mathrm{ReCl}_{2}\left\{\mathrm{NNC}(\mathrm{O}) \mathrm{C}_{6} \mathrm{H}_{5}\right\}(\mathrm{Hpz})_{2}\left(\mathrm{PPh}_{3}\right)\right](\mathbf{B}),[\mathrm{ReClF}$ $\left.\left\{\mathrm{NNC}(\mathrm{O}) \mathrm{C}_{6} \mathrm{H}_{5}\right\}(\mathrm{Hpz})_{2}\left(\mathrm{PPh}_{3}\right)\right](\mathbf{C})$, and their precursor $\left[\mathrm{ReOCl}_{3}\left(\mathrm{PPh}_{3}\right)_{2}\right](\mathbf{D})$, immobilized on 3 -aminopropyl-functionalized silica have been prepared and used for neat $\mathrm{O}_{2}$ oxidation of $n$-hexane and $n$-heptane mainly to the corresponding alcohols and, in lower amounts, ketones. The supported catalyst $\mathrm{C}$, with fluoro- and diazenido-ligands, exhibits the highest activity for both alkanes (overall turnover numbers (TONs) up to $3.8 \times 10^{3}$ and $2.5 \times 10^{3}$, for $n$-hexane and $n$-heptane, respectively) and can be reused in consecutive catalytic cycles. Improved conversion was observed after addition of hetero-carboxylate co-catalysts. A free-radical-based mechanism is proposed to explain the product formation.
\end{abstract}

Keywords: rhenium; scorpionate derivative; immobilization; supported catalysis; n-alkane; oxidation; molecular oxygen; product selectivity; radical mechanism

\section{Introduction}

Hydrocarbon oxy-functionalizations constitute very important industrial processes due to the huge worldwide demand for oxidized products [1-5]. Homogeneous metal complex catalysts have been successfully applied in various oxidation reactions but their separation from the liquid-phase reaction mixture is often a big challenge [6-9]. Thus, we aim to develop supported catalysts that combine the adaptability and activity of homogeneous ones with the ease of separation and catalyst recyclability of heterogeneous ones, making them potentially more appealing for chemical industry $[10,11]$. Oxidation with molecular oxygen (or air) is very attractive due to its abundant availability in the atmosphere and from an economical point of view in comparison with other oxidants. Aerobic alkane oxidations normally require, apart from suitable catalysts, the use of high temperatures and pressures, and, under such conditions, alkanes usually undergo competitive reactions-cracking, isomerization, dehydrogenation, cyclization, metathesis, oligomerization, and polymerization [12-14]. These types of difficulties are encountered, e.g., in the case of linear and liquid $C_{6}$ (n-hexane) and $C_{7}$ (n-heptane) alkanes $[13,14]$ which are important components of naphtha, with oxy-functionalized derivatives that have commercial interest and, therefore, have been selected for the current study. 
Many metal complex catalysts have been successfully used for $\mathrm{C}-\mathrm{H}$ bond activation of alkanes with molecular oxygen [12,13,15-20]—in particular, MTO (methyltrioxorhenium trioxide), which is a commercial catalyst that also has high activity for olefin oxidations [21].

The heterogeneous partial oxidation of $n$-hexane with $\mathrm{O}_{2}$ was reported for a $\mathrm{Pt}-10 \% \mathrm{Rh}$ catalyst in a single-gauze auto-thermal reactor, at a typical preheat temperature of the feed gases of $200{ }^{\circ} \mathrm{C}$, producing various oxygenates (70\% selectivity) including 2,5-dimethyltetrahydrofuran (ca. $35 \%$ selectivity), with $n$-hexane and oxygen conversions of 20 and $100 \%$, respectively [22]. In another case, the oxidation of $n$-hexane with $\mathrm{O}_{2}$ catalysed by Mn-exchanged zeolites at $130{ }^{\circ} \mathrm{C}$ [23] led to a diversity of oxidation products (e.g., 3-hexanone, 2-hexanone, hexanal, 3-hexanol, 2-hexanol, acetic, propionic, butyric, valeric, and hexanoic acids). Other cases include the oxidation of $n$-hexane (and cyclohexane) by air and oxygen mixtures, in the absence and in the presence of $\mathrm{Al}_{2} \mathrm{O}_{3}, \mathrm{Ni}_{2} \mathrm{O}_{3}, \mathrm{MoO}_{3}, \mathrm{CuCl}_{2}$, and ZSM- $5+1.2 \% \mathrm{Fe}_{2} \mathrm{O}_{3}$, in a bubble plasma reactor, leading to a diversity of hydroxylated and carbonyl compounds such as alcohols, aldehydes, and ketones [24]. In the case of $n$-heptane, $\mathrm{SiO}_{2}-\mathrm{Zr}$ complex catalysts also show a broad product distribution [19]. Vanadium complex catalysts supported on carbamate-modified silica gel originate several oxygenates (2- and 4-heptanone, 2- and 1-heptanol, trans-3-hepten-2-one, octan-2-ol, octanoic acid, heptaldehyde, and heptanoic acid) from n-heptane [11]. Several types of nonmetallic molecular sieves (e.g., BEA, MCM-41, SAPO-5, and SAPO-11) have also been used as catalysts for $n$-heptane aerobic (with oxygen) oxidation, between $300{ }^{\circ} \mathrm{C}$ and $400{ }^{\circ} \mathrm{C}$, leading to a mixture of heterocyclic compounds (2-methyl-5-ethyl furan and 2,6-dimethylpyran), heptanones, 4-methyl-1,4-hexadiene, 2,4-dimethyl-1,3-pentadiene, and 1-hepten-4-ol [24].

Recently, we have also reported SBA-15-Co complex catalysts for the $\mathrm{O}_{2}$ oxidation of $n$-hexane and $n$-heptane at $150-200{ }^{\circ} \mathrm{C}$ (conversion of $19.6 \%$ and $17.3 \%$, respectively) [20]. SBA-15-Re metal catalysts have been also used for direct $n$-hexane (and other $n$-alkanes) oxidation in the presence of $\mathrm{O}_{2}$ with a high selectivity to hexane-2-one (up to $62 \%$ ) at $150{ }^{\circ} \mathrm{C}$ [25]. Other metals were also investigated for catalysed $n$-hexane oxidation with $\mathrm{O}_{2}$, namely modified $\mathrm{SiO}_{2}$-oxovanadium complexes, leading mainly to hexan-2-one with high $58 \%$ selectivity at $160{ }^{\circ} \mathrm{C}$ [26]. A Schiff base isocyanate-modified $\mathrm{SiO}_{2} / \mathrm{V}$ catalyst was used for the same reaction, with an overall conversion of ca. $10 \%$ to alcohols, ketones, and acids at $150^{\circ} \mathrm{C}$ [27].

Previously, we had found that the rhenium pyrazole complex $\left[\operatorname{ReClF}\left\{\mathrm{NNC}(\mathrm{O}) \mathrm{C}_{6} \mathrm{H}_{5}\right\}(\mathrm{Hpz})_{2}\left(\mathrm{PPh}_{3}\right)\right]$ (C) (where $\mathrm{Hpz}$ is pyrazole) supported on modified $\mathrm{SiO}_{2}$, is a catalyst for the oxidation of cycloalkanes with a good overall conversion of $16 \%$ at $150{ }^{\circ} \mathrm{C}$ [17]. This complex is part of a set of pyrazole derivatives of $\mathrm{C}$-scorpionate complexes. In fact, attempts to synthesize a rhenium complex with a hydrotris(1-pyrazolyl)methane ligand from the reaction with the benzoylhydrazido rhenium(V) chelate (in stoichiometric amounts) in refluxing methanol led to the formation of the corresponding pyrazole derivatives $[28,29]$. The pyrazole ligand is derived from the rupture of a $\mathrm{C}\left(\mathrm{sp}^{3}\right)-\mathrm{N}$ bond in the hydrotris-(1-pyrazolyl)methane compound-conceivably by hydrolysis of the C-scorpionate.

Herein, we address the anchorage of the pyrazole Re-complexes, $\left[\operatorname{ReCl}_{2}\left\{\mathrm{NNC}(\mathrm{O}) \mathrm{C}_{6} \mathrm{H}_{5}\right\}\right.$ $\left.(\mathrm{Hpz})\left(\mathrm{PPh}_{3}\right)_{2}\right](\mathbf{A}),\left[\mathrm{ReCl}_{2}\left\{\mathrm{NNC}(\mathrm{O}) \mathrm{C}_{6} \mathrm{H}_{5}\right\}(\mathrm{Hpz})_{2}\left(\mathrm{PPh}_{3}\right)\right](\mathbf{B})$, and [ReClF $\left.\left\{\mathrm{NNC}(\mathrm{O}) \mathrm{C}_{6} \mathrm{H}_{5}\right\}(\mathrm{Hpz})_{2}\left(\mathrm{PPh}_{3}\right)\right]$ (C), and their precursor $\left[\mathrm{ReOCl}_{3}\left(\mathrm{PPh}_{3}\right)_{2}\right]$ (D) $[17,28-31]$ on 3-aminopropyl-functionalized $\mathrm{SiO}_{2}$ (Schemes 1 and 2), and evaluate them as reusable heterogeneous catalysts for the neat oxy-functionalization of $n$-hexane and $n$-heptane in the presence of molecular oxygen under pressure in a batch reactor under low temperature. 
<smiles>O=C(N=N[Z6](Cl)(Cl)C(Cl)(c1ccccc1)[n+]1ccc[nH]1)c1ccccc1</smiles>

$\mathbf{A}$<smiles></smiles>

B

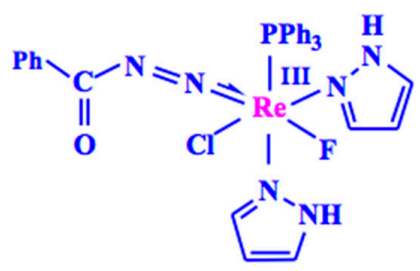

C

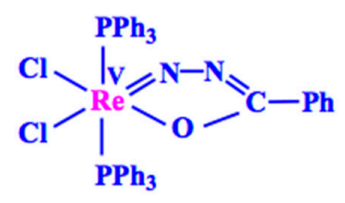

D

Scheme 1. Schematic representations of rhenium complexes A to D.

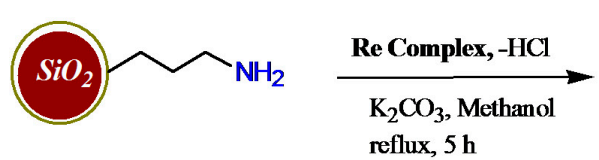

Aminopropyl-modified silica

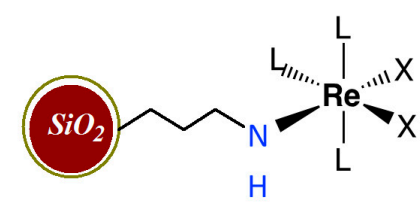

Final Hybrid Re Catalyst

Scheme 2. Formation of hybrid materials by immobilization of rhenium complexes at 3-aminopropyl-modified silica.

\section{Results}

\subsection{Catalyst Synthesis and Characterization}

The aim of the current study was to assess the catalytic activity and the recyclability of the rhenium complexes $\left[\operatorname{ReCl}_{2}\left\{\mathrm{NNC}(\mathrm{O}) \mathrm{C}_{6} \mathrm{H}_{5}\right\}(\mathrm{Hpz})\left(\mathrm{PPh}_{3}\right)_{2}\right]$ (A) (where $\mathrm{Hpz}$ is pyrazole), $\left[\mathrm{ReCl}_{2}\left\{\mathrm{NNC}(\mathrm{O}) \mathrm{C}_{6} \mathrm{H}_{5}\right\}(\mathrm{Hpz})_{2}\left(\mathrm{PPh}_{3}\right)\right] \quad(\mathbf{B}), \quad\left[\operatorname{ReClF}\left\{\mathrm{NNC}(\mathrm{O}) \mathrm{C}_{6} \mathrm{H}_{5}\right\}(\mathrm{Hpz})_{2}\left(\mathrm{PPh}_{3}\right)\right] \quad(\mathbf{C}), \quad$ and $\left[\mathrm{ReOCl}_{3}\left(\mathrm{PPh}_{3}\right)_{2}\right]$ (D) anchored on 3-aminopropyl-functionalized silica (Schemes 1 and 2) for the partial oxidation of $n$-alkanes. Therefore, $n$-hexane and $n$-heptane were chosen for oxidation with a cheap and green oxidant (molecular oxygen).

Complexes A-D (Scheme 1) were synthesized according to a reported procedure $[17,29,31]$ and characterized by spectroscopic and analytic techniques. Then, they were supported on 3-aminopropyl-functionalized silica by replacement of a chloride ligand by the N-donor silica via a condensation reaction in the presence of $\mathrm{K}_{2} \mathrm{CO}_{3}$ [15]. The loss of one chloride ligand from the $\mathrm{Re}$ coordination sphere was confirmed by far-IR spectroscopy $\left(400-200 \mathrm{~cm}^{-1}\right)$ : the spectra of A, B, and $\mathrm{D}$ display only one (280-325 $\mathrm{cm}^{-1}$ range) of the two $\mathrm{Re}-\mathrm{Cl}$ bands found in the non-immobilized complexes; in the spectrum of $\mathrm{C}$, no band could be detected for the $\mathrm{Re}-\mathrm{Cl}$ bond in the range 400-200 $\mathrm{cm}^{-1}$.

Morphological characterization of the respective chemical compositions [using scanning electron microscopy (SEM)/energy-dispersive X-ray spectroscopy (EDS)] and thermal stability [using thermogravimetric analysis (TGA)] of the most active Re catalyst $C$ are presented. SEM images (Figure 1A) of the Re complex $\mathbf{C}$ supported on modified $\mathrm{SiO}_{2}$ show light clusters of Re complex on the 
dark background, i.e., the silica surface. The presence of metal complex over the $\mathrm{SiO}_{2}$ support matrix was confirmed in the EDS detector of SEM (showing $0.23 \%$ of Re, Figure 1B).

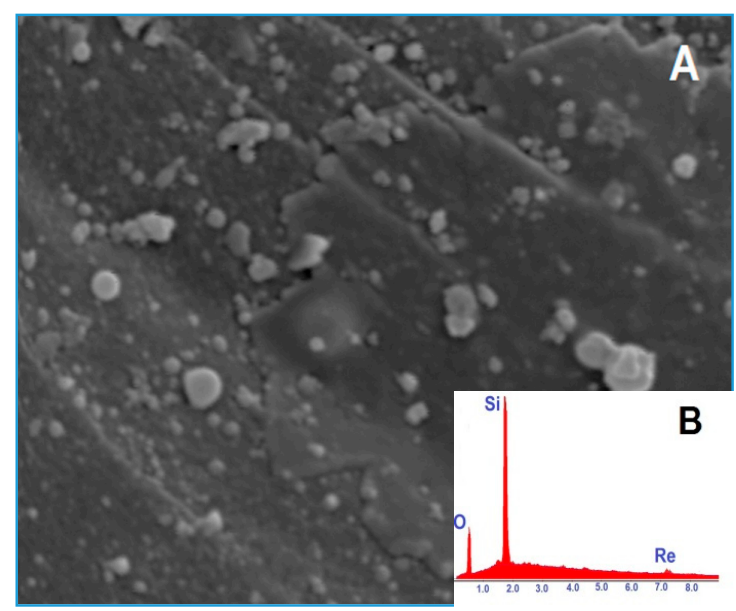

Figure 1. Scanning Electron Microscopy (SEM) image of C (A) and presence of Re on support surface, confirmed by SEM/EDS spectrum (B).

The thermal stability of the hybrid materials was tested by TGA (Figure 2). Initially and below $100{ }^{\circ} \mathrm{C}$, a slight weight loss was observed, most likely due to absorbed moisture. After that, a significant weight loss was observed only in the range of ca. 200 to $245^{\circ} \mathrm{C}$, most likely due to decomposition of the anchored metal complex species over the silica support. The order of stability is $\mathbf{C}>\mathbf{D}>\mathbf{A}>\mathbf{B}$. No more complex decay was observed above that temperature range. These Re catalysts are stable under the operating temperature range of $100-200^{\circ} \mathrm{C}$ for the current catalytic study.

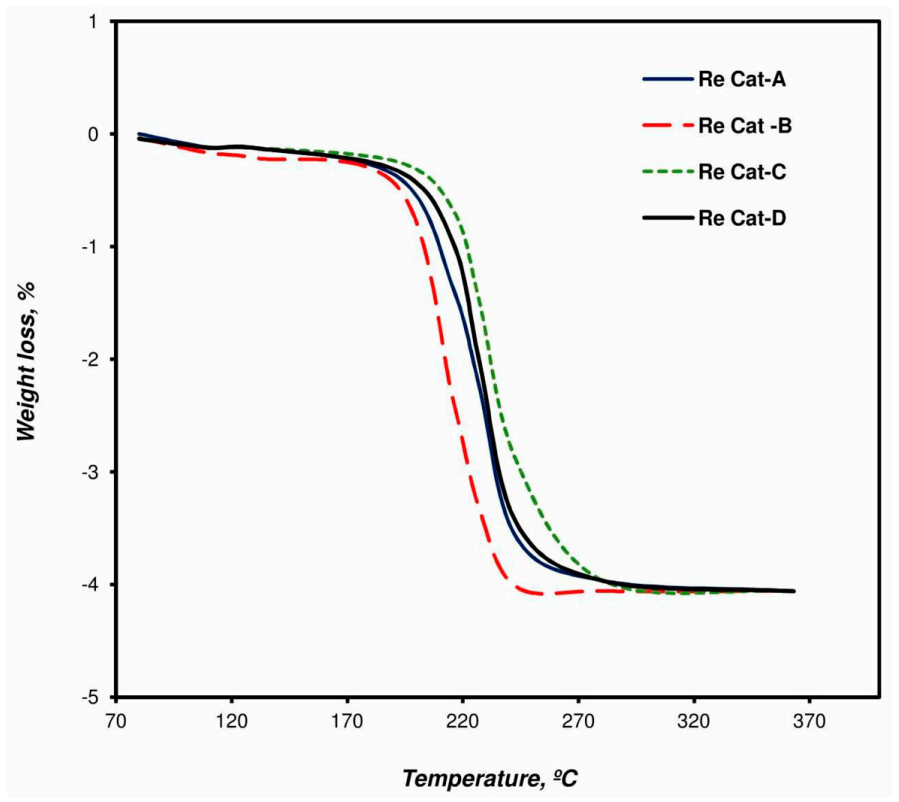

Figure 2. Thermal gravimetric analysis (TGA) graph of supported rhenium complex catalysts A-D.

\subsection{Catalytic Batch Oxidation of Alkanes}

We have found that the above supported Re complexes $\mathbf{A}$ to $\mathbf{D}$ act as catalysts for the partial oxidation of neat $n$-hexane and $n$-heptane by molecular oxygen, under relatively mild conditions 
(typical temperature of ca. $150-160^{\circ} \mathrm{C}$ and typical $\mathrm{O}_{2}$ pressure of ca. $10-12 \mathrm{~atm}$ ), to the corresponding alcohols and, in lower amounts, ketones, without needing any additional solvent or additive.

Normally, saturated hydrocarbons require harsh reaction conditions for oxy-functionalization, but we have achieved a high catalytic conversion rate at a relatively low temperature, as shown in Table 1, in the presence of A-D supported on functionalized silica-namely, 5.2-12.6\% conversion for $n$-hexane and $4.0-10.0 \%$ for $n$-heptane.

Table 1. Selected data ${ }^{a}$ for neat $C_{6}$ and $C_{7} n$-alkane oxidations with di-oxygen catalysed by hybrid Re catalysts.

\begin{tabular}{|c|c|c|c|c|c|c|c|}
\hline \multirow{2}{*}{ Alkane } & \multirow{2}{*}{ Run } & \multirow{2}{*}{ Catalyst } & \multicolumn{5}{|c|}{ Conversion $(\%)$} \\
\hline & & & 2-Hexanol & 3-Hexanol & 2-Hexanone & Hexanoic Acid & Total \\
\hline \multirow{4}{*}{ n-hexane } & 1 & $\mathbf{A}$ & 3.0 & 1.5 & 1.7 & 0.6 & 7.4 \\
\hline & 2 & B & 3.9 & 2.0 & 2.2 & 0.8 & 9.3 \\
\hline & 3 & C & 5.1 & 2.5 & 3.1 & 1.0 & 12.6 \\
\hline & 4 & D & 2.1 & 1.1 & 1.3 & 0.4 & 5.2 \\
\hline \multirow{5}{*}{ n-heptane } & & & 2-Heptanol & 4-Heptanol & 2-Heptanone & 3-Heptanone & \\
\hline & 5 & A & 1.1 & 3.0 & 1.0 & 0.4 & 5.9 \\
\hline & 6 & B & 1.6 & 4.0 & 1.3 & 0.6 & 8.2 \\
\hline & 7 & $\mathrm{C}$ & 2.0 & 5.5 & 1.4 & 0.7 & 10.0 \\
\hline & 8 & D & 0.8 & 2.2 & 0.6 & 0.3 & 4.0 \\
\hline
\end{tabular}

For both substrates, the heterogenized pyrazole-fluoro Re complex $\left[\operatorname{ReClF}\left\{\mathrm{N}_{2} \mathrm{C}(\mathrm{O}) \mathrm{Ph}\right\}\right.$ $\left.(\mathrm{Hpz})_{2}\left(\mathrm{PPh}_{3}\right)\right] \mathrm{C}$ provides the most active catalyst leading to overall $n$-hexane conversion of $12.6 \%$ (5.1\% to 2-hexanol, $2.5 \%$ to 3-hexanol, 3.1\% to 2-hexanone, and 1.0\% to hexanoic acid, entry 3, Table 1 and Figure S1, ESI) and overall $n$-heptane conversion of $10 \%$ (2.0\% to 2-heptanol, $5.5 \%$ to 4 -heptanol, $1.4 \%$ to 2-heptanone, $0.7 \%$ to 3-heptanone, entry 7, Table 1 and Figure S1, ESI), for $p\left(\mathrm{O}_{2}\right)$ of 12 or 10, at 150 or $160^{\circ} \mathrm{C}$, respectively, upon $8 \mathrm{~h}$ reaction time. Such conversions correspond to overall selectivities towards the alcohols of $60 \%$ and $75 \%$ for the oxidations of $n$-hexane and $n$-heptane, respectively.

Moreover, remarkable overall turnover numbers (TONs) (number of moles of products per mole of Re complex $\mathrm{C}$ loaded on the modified silica gel) of ca. $3.8 \times 10^{3}$ for $n$-hexane and $2.5 \times 10^{3}$ for $n$-heptane (for runs 3 and 7, Table 1 , respectively) were achieved. Hexanoic acid, in small amounts, was a minor observed product of the $n$-hexane oxidation, whereas no isomerization, dehydrocyclization, or cracking products were found. Identical product distribution was found for $n$-hexane when subject to oxidation catalyzed by tricarbonyl $\operatorname{Re}(\mathrm{V})$ complexes anchored on modified SBA-15 [25].

Good $n$-alkanes conversions with the supported complex $\mathbf{C}$ were also reported [32] for the following homogeneous systems: (i) peroxidative oxidation of cyclohexane with $\mathrm{H}_{2} \mathrm{O}_{2}$ oxidant, and (ii) ethane oxidation to acetic acid with $\mathrm{K}_{2} \mathrm{~S}_{2} \mathrm{O}_{8}$ oxidant in trifluoroacetic acid.

The catalytic activity of the A-D complexes for the oxidation of $n$-hexane and $n$-heptane was also checked under homogeneous conditions, but the conversions were lower than those achieved in the heterogeneous system. The fluoro-chloro complex $\left[\operatorname{ReClF}\left\{\mathrm{N}_{2} \mathrm{C}(\mathrm{O}) \mathrm{Ph}\right\}(\mathrm{Hpz})_{2}\left(\mathrm{PPh}_{3}\right)\right] \mathrm{C}$ still provides the most active catalyst (maximum overall conversions of ca. $4 \%$ and $3 \%$ with respect to $n$-hexane and $n$-heptane oxidations, respectively) within the studied Re species. The overall selectivity towards alcohols was maintained. The higher activity of the fluoro complex $\mathbf{C}$ in comparison with the related chloro complexes $\mathbf{A}, \mathbf{B}$, and $\mathbf{D}$ is in accord with the observed [33] catalytic behaviors for ethane and cyclohexane oxidations $[17,32]$. It possibly concerns the overall stronger electron-donor character of the fluoride ligand relative to chloride, as found by a previous detailed electrochemical study [29], thus favoring the oxidation (by $\mathrm{O}_{2}$ ) of the complex to a higher metal oxidation state and promoting the alkane oxidation. 
Blank experiments for both $n$-alkanes were run in the absence of catalyst and led to lower overall conversion of 2.2 and $1.6 \%$ for $\mathrm{C}_{6}$ and $\mathrm{C}_{7}$, respectively. This confirms that our catalysts are playing a key role for this aerobic oxidation process.

The most active supported catalyst $\mathbf{C}$ was selected for optimizing and recycling studies and the percentage of metal variation was measured by Atomic Absorption Spectroscopy (AAS) analysis. The AAS shows that the fresh Re catalyst has $0.29 \pm 0.02 \%$ weight Re content.

The effect of various parameters such as temperature, $\mathrm{O}_{2}$ pressure, reaction time, and catalyst amount were examined for the most active supported catalyst $\mathbf{C}$. Improved conversion results with an heteroaromatic acid (as a co-catalyst) and catalyst recycling are also discussed (see below). All the catalytic results are summarized in Table 1 and Figures 3-12.

\subsection{Optimization of Reaction Conditions for the Oxidations}

\subsubsection{Effect of the Temperature}

The reaction temperature study was performed within the range of $90-190{ }^{\circ} \mathrm{C}$ or $100-200{ }^{\circ} \mathrm{C}$ for the oxidation of $n$-hexane (Figure 3 ) or $n$-heptane (Figure 4), at $p\left(\mathrm{O}_{2}\right)=12 \mathrm{~atm}$ or $10 \mathrm{~atm}$, respectively, with $8 \mathrm{~h}$ duration. An increase of temperature leads to an enhancement of the overall conversion of the alkanes, which reaches the values of $19.1 \%$ and $16.2 \%$, respectively, under those conditions. The conversions into the alcohol and ketone products also increase with the temperature. However, the reaction temperature was not allowed to go beyond $190{ }^{\circ} \mathrm{C}$ for hexane and $200{ }^{\circ} \mathrm{C}$ for heptane, since an unidentified black charring material appeared.

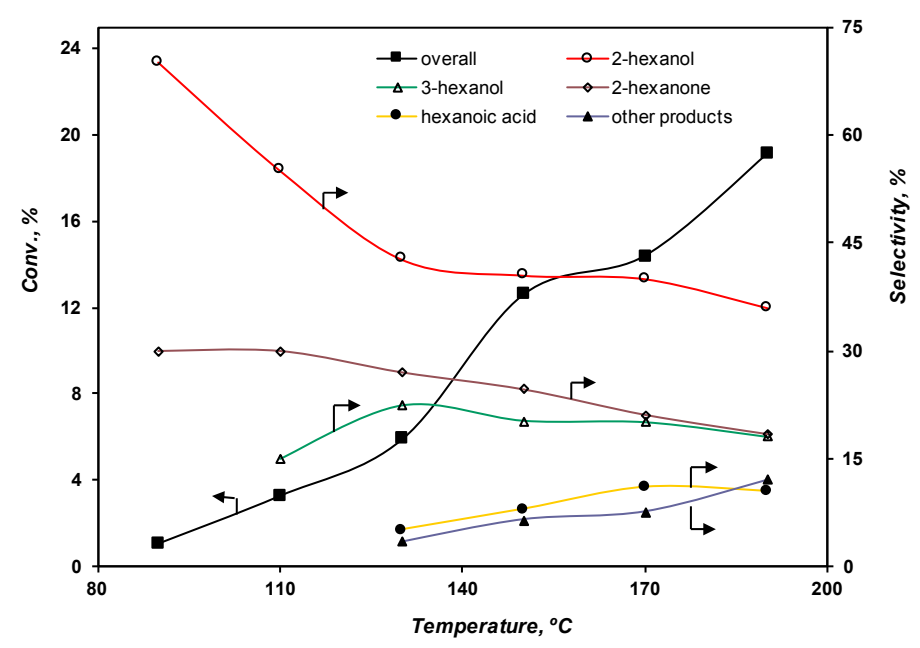

Figure 3. Reaction temperature effect on the conversion and selectivity of $n$-hexane oxidation with $\mathrm{O}_{2}$ catalyzed by $\mathrm{C}\left(p\left(\mathrm{O}_{2}\right)=12 \mathrm{~atm}, 8 \mathrm{~h}\right)$. Conv.: conversion.

The best overall selectivity of $93 \%$ (overall conversion $12.6 \%$ ) of the main products (alcohols, ketone, and acid; Table 1) was obtained at $150{ }^{\circ} \mathrm{C}$ for hexane oxidation, with the following selectivities: 2-hexanol, 40.5\%; 3-hexanol, 20.2\%; 2-hexanone, 24.6\%; and hexanoic acid, 8.0\%. A mixture of unidentified minor or by-products $(6.5 \%)$ was also obtained. For $n$-heptane, the highest overall selectivity of $96 \%$ of the main products (alcohols and ketones, Table 1 ) and overall conversion 10\% was observed at $160{ }^{\circ} \mathrm{C}$. The main product selectivities at this temperature are 2-heptanol, 20.0\%; 4-heptanol, $55 \%$; 2-heptanone, $14 \%$; and 3-heptanone, $7.0 \%$. Above this temperature- $170{ }^{\circ} \mathrm{C}$ for hexane and $180{ }^{\circ} \mathrm{C}$ for $n$-heptane-the overall conversion increases to $14.4 \%$ and $12.4 \%$ but the selectivity of the main products falls to $92.1 \%$ and $90.1 \%$ for hexane and heptane oxidation, respectively. At the higher temperature of $190^{\circ} \mathrm{C}$, the main product (alcohols, ketone, and acid) selectivities decreased significantly (2-hexanol, 36.0\%; 3-hexanol, 18.0\%; 2-hexanone, 18.3\%; and hexanoic acid, $10.5 \%$ ) due 
to an increasing amount $(12.0 \%)$ of by-products. The same trend was also observed for heptane at $200{ }^{\circ} \mathrm{C}$, where the overall conversion increased to $16.2 \%$ but the main product (alcohols and ketones) selectivity $(84.0 \%)$ decreased significantly.

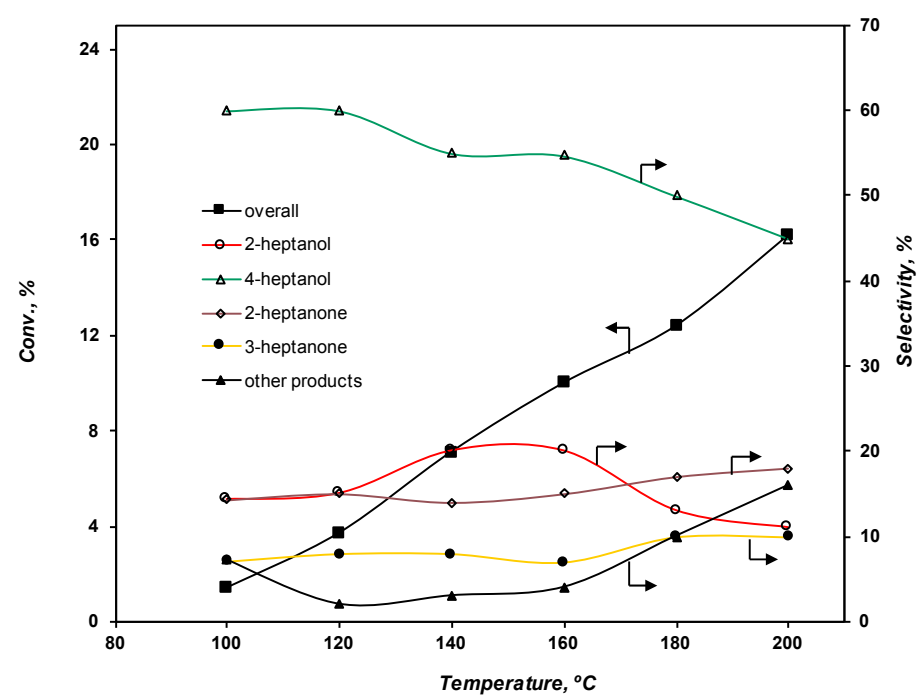

Figure 4. Reaction temperature effect on the conversion and selectivity of $n$-heptane oxidation with $\mathrm{O}_{2}$ catalyzed by $\mathrm{C}\left(p\left(\mathrm{O}_{2}\right)=10 \mathrm{~atm}, 8 \mathrm{~h}\right)$.

The best selectivity (40.5\%) and conversion (12.6\%) of the main $n$-hexane product, i.e., 2-hexanol, was obtained at $150{ }^{\circ} \mathrm{C}$. For $n$-heptane, the best selectivity (55\%, with the conversion of $\left.10.0 \%\right)$ for the main product, i.e., 4-heptanol, was observed at $160{ }^{\circ} \mathrm{C}$. Above those temperatures, the generation of by-products increased with the subsequent drop in the formation of the above main products. Hence, temperature effect plays a lead role for both $n$-alkane selectivity and conversion: lower temperatures correspond to lower conversions but higher selectivities towards alcohols and ketones.

\subsubsection{Effect of the $\mathrm{O}_{2}$ Pressure}

The effect of $\mathrm{O}_{2}$ pressure was examined from 6 atm to 20 atm for the oxidation of $n$-hexane (Figure 5) and $n$-heptane (Figure 6) and Table 1 . The overall conversions and the conversions into the main products markedly increase with $p\left(\mathrm{O}_{2}\right)$, the former reaching values of $20.8 \%$ and $16.8 \%$, at maximum 20 atm pressure, respectively. However, the selectivities of the main products do not follow this trend: that of 2-hexanol decreases from $50.1 \%$ to $38.0 \%$ for $p\left(\mathrm{O}_{2}\right)$ of 10 and 20 atm, while that of 4-heptanol decreases from $56 \%$ to $51 \%$, on account of the increasing amount of by-products produced upon increasing the $\mathrm{O}_{2}$ pressure. A good overall conversion of $12.6 \%$ with a high selectivity of $93 \%$ of main products (alcohols, ketone, and acid; Table 1) was obtained at 12 atm for hexane oxidation. For the $n$-heptane oxidation, the overall conversion of $10.0 \%$ with the high selectivity $96 \%$ of main products (alcohols and ketones, Table 1) was obtained at $12 \mathrm{~atm}$ pressure. The promotion of the overall conversion with the oxygen pressure is consistent with the increase of the solubility of this gas with pressure. 


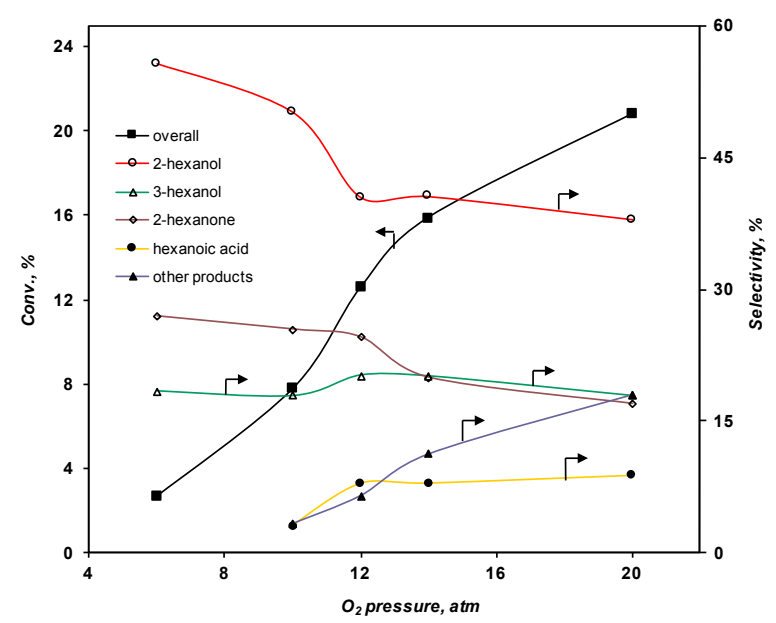

Figure 5. $\mathrm{O}_{2}$ pressure effect on the conversion and selectivity of $n$-hexane oxidation catalyzed by $\mathbf{C}$ $\left(150{ }^{\circ} \mathrm{C}, 8 \mathrm{~h}\right)$.

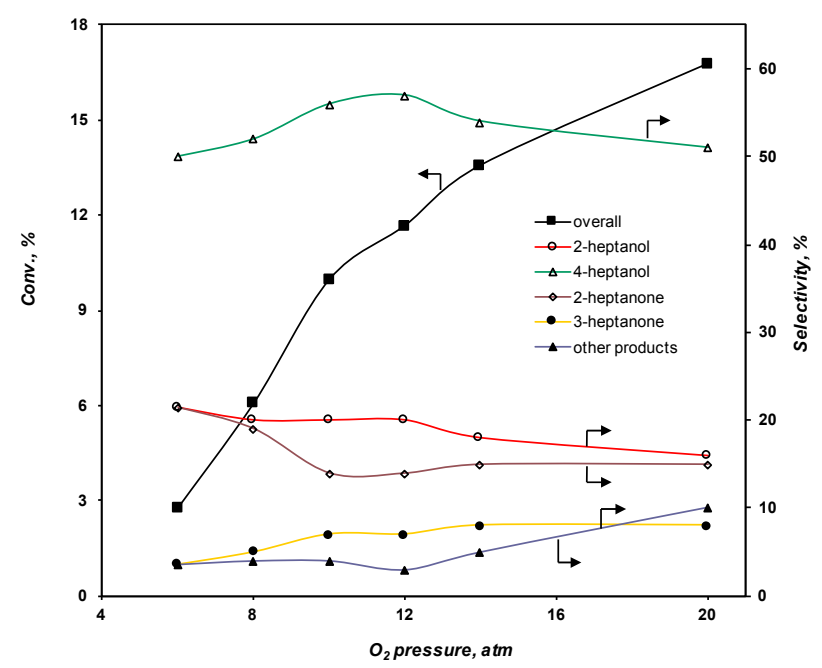

Figure 6. $\mathrm{O}_{2}$ pressure effect on the conversion and selectivity of $n$-heptane oxidation catalyzed by $\mathbf{C}$ $\left(160^{\circ} \mathrm{C}, 8 \mathrm{~h}\right)$.

\subsubsection{Effect of the Reaction Time}

The reaction time study concerned the period from $4 \mathrm{~h}$ to $16 \mathrm{~h}$ at $150{ }^{\circ} \mathrm{C}$ for $n$-hexane (Figure 7 ) and from $4 \mathrm{~h}$ to $24 \mathrm{~h}$ at $160^{\circ} \mathrm{C}$ for $n$-heptane (Figure 8), under constant $p\left(\mathrm{O}_{2}\right)$ (12 or $10 \mathrm{~atm}$, respectively). Similar trends for both alkanes can be recognized, i.e., the overall conversions increase with the time e.g., from $2.9 \%$ to $17.3 \%$ for hexane and $1.9 \%$ to $22.1 \%$ for heptane. Initially ( $4 \mathrm{~h}$ time), the main product selectivity was very high (2-hexanol, 56\%; 4-heptanol 58\%). It reduces from $47.0 \%$ (at $6 \mathrm{~h}$ ) to $22.5 \%$ (at $16 \mathrm{~h}$ ) for 2-hexanol. In the 4-heptanol case, there was no change observed till $10 \mathrm{~h}$ (58\% selectivity). Afterward, it reduces from $51.0 \%$ to $38 \%$ selectivity at the reaction times of $16 \mathrm{~h}$ and $24 \mathrm{~h}$, respectively. The formation of by-products increases along with the time; hence, the selectivities towards the main products tend to decrease. 


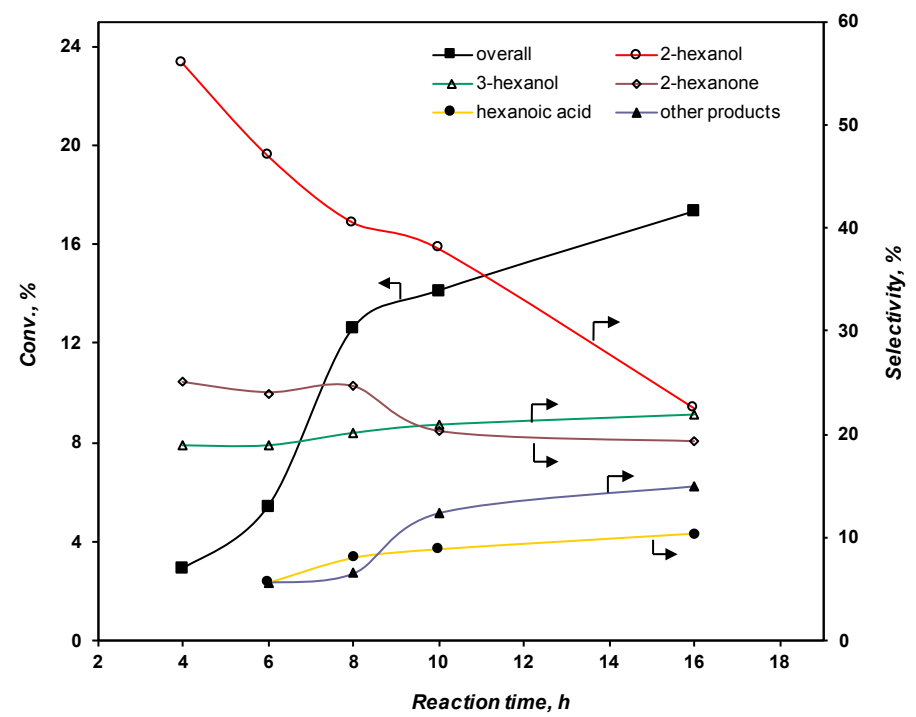

Figure 7. Reaction time effect on the conversion and selectivity of $n$-hexane oxidation with $\mathrm{O}_{2}$ catalyzed by $\mathrm{C}\left(150^{\circ} \mathrm{C}, p\left(\mathrm{O}_{2}\right)=12 \mathrm{~atm}\right)$.

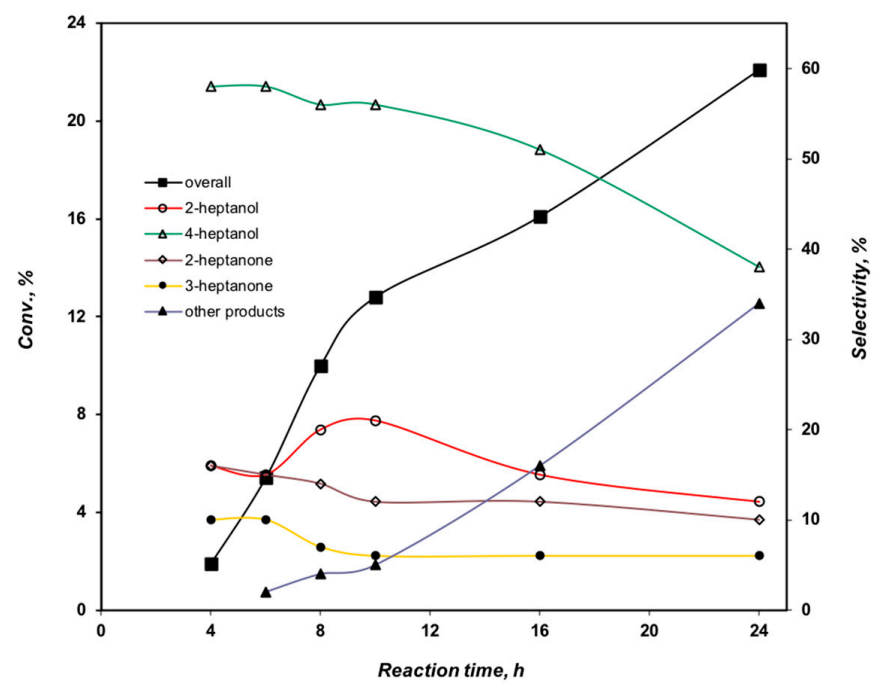

Figure 8. Reaction time effect on the conversion and selectivity of $n$-heptane oxidation with $\mathrm{O}_{2}$ catalyzed by $\mathrm{C}\left(160^{\circ} \mathrm{C}, p\left(\mathrm{O}_{2}\right)=10 \mathrm{~atm}\right)$.

\subsubsection{Effect of the Catalyst Amount}

The conversions of both $n$-alkanes into the oxidation products are promoted by increasing the amount of the supported catalyst $\mathbf{C}$ (Figure 9 for $n$-hexane and Figure 10 for $n$-heptane). Therefore, increasing the amount of catalyst from $5 \mathrm{mg}$ to $45 \mathrm{mg}$ led to a growth of overall conversion from $2.7 \%$ to $20.8 \%$ (for $n$-hexane) and from $4.2 \%$ to $18.3 \%$ (for $n$-heptane). However, and as expected, the alcohol and ketone selectivity (2-hexanol, $54 \%$; 3 -hexanol, $26 \%$ and 2-hexanone, $20 \%$, for $n$-hexane) decreased as the amount of catalyst increased (Figure 9). In the case of $n$-heptane, this change is not so evident (Figure 10). 


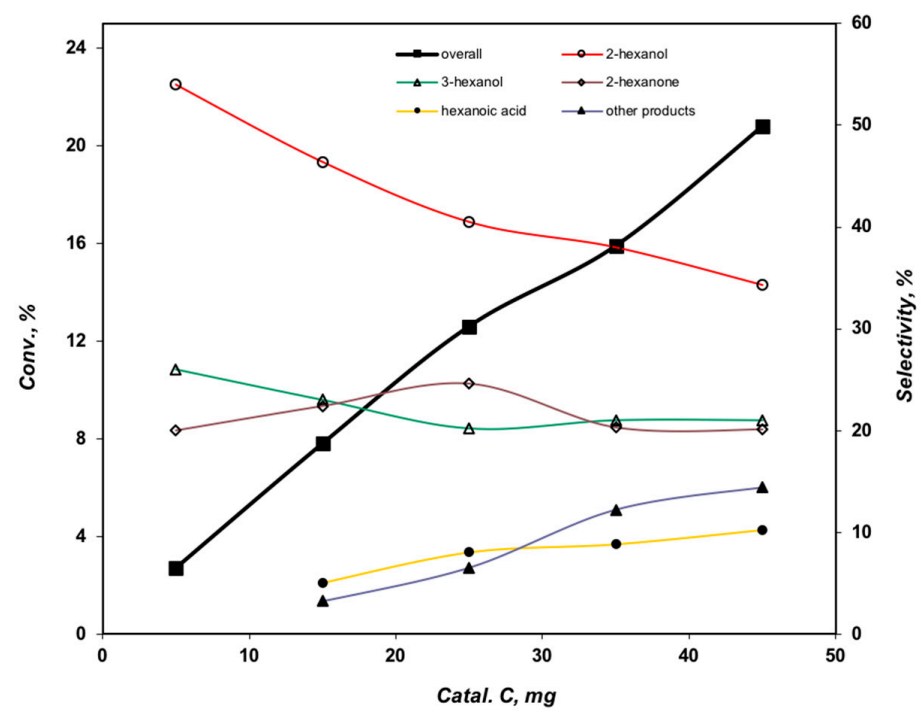

Figure 9. Effect of amount of $\mathrm{C}$ on the conversion and selectivity of $n$-hexane oxidation with $\mathrm{O}_{2}\left(150{ }^{\circ} \mathrm{C}\right.$, $\left.p\left(\mathrm{O}_{2}\right)=12 \mathrm{~atm}, 8 \mathrm{~h}\right)$. Catal.: catalyst.

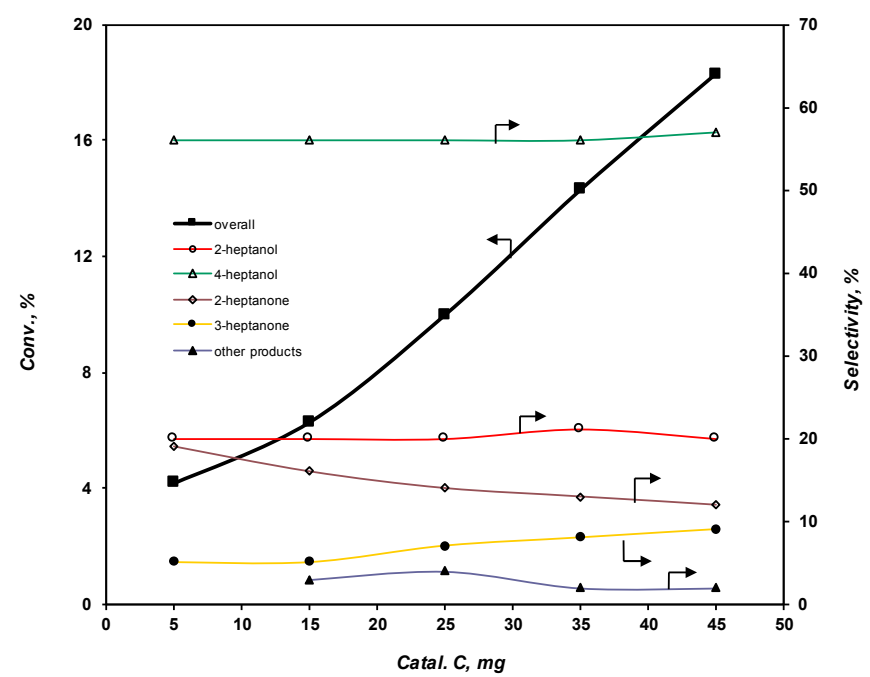

Figure 10. Effect of amount of $\mathrm{C}$ on the conversion and selectivity of $n$-heptane oxidation with $\mathrm{O}_{2}$ $\left(160{ }^{\circ} \mathrm{C}, p\left(\mathrm{O}_{2}\right)=10 \mathrm{~atm}, 8 \mathrm{~h}\right)$.

\subsubsection{Effect of the Co-Catalyst}

To improve the conversion, some heteroaromatic carboxylic acids, i.e., 3-amino-2-pyrazinecarboxylic acid, 2,6-pyrazinedicarboxylic acid, 2,3-pyrazinedicarboxylic acid, pyrazinecarboxylic acid (PCA), and picolinic acid, were tested as co-catalysts (Figure 11 for $n$-hexane and Figure 12 for $n$-heptane). The best conversion was observed with pyrazinecarboxylic acid for both alkanes. Under similar conditions (Table 1, run 3) PCA quite significantly promotes the overall conversion from $12.6 \%$ to $17.5 \%$ for $n$-hexane oxidation. The main products, 2 - and 3-hexanol, increased from $7.6 \%$ to $12.7 \%$, and 2-hexanone from 3.1\% to 3.7\%. For $n$-heptane, a similar PCA effect was observed: the overall conversion increased from $10.0 \%$ to $15.9 \%$. The conversions to the major products, i.e., to alcohols (2- and 4-heptanol), increased from $7.5 \%$ to $11.8 \%$, and to ketones (2- and 3-heptanone) increased from $2.1 \%$ to $3.2 \%$. The other tested acids were less active for both alkanes. 


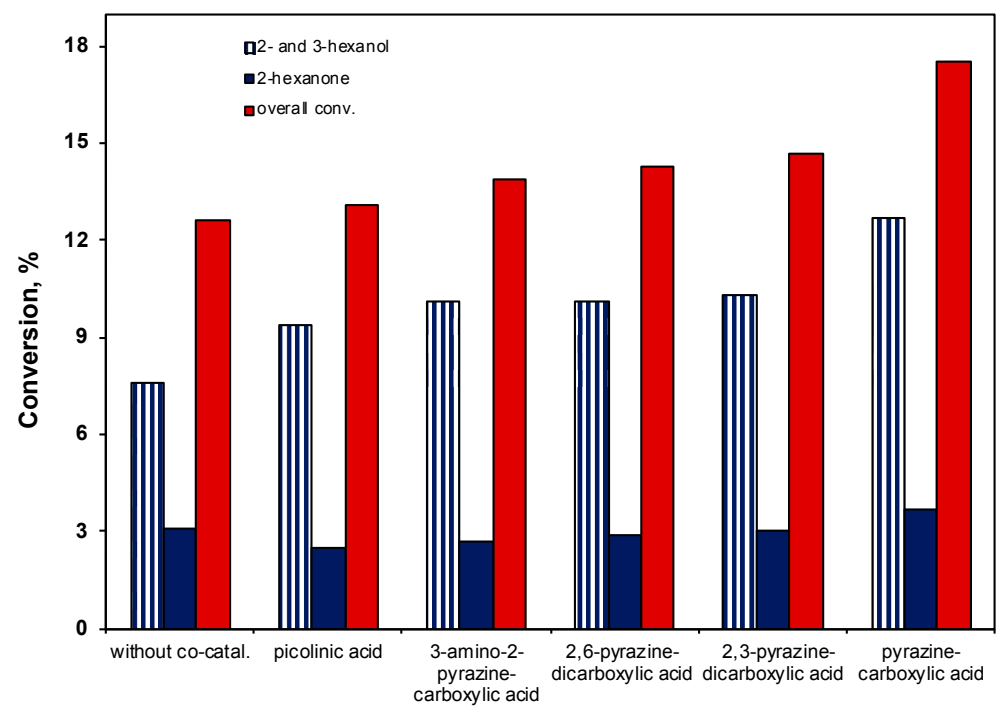

Figure 11. Effect of hetero-aromatic carboxylic acids (as co-catalysts) on conversion of $n$-hexane oxidation with $\mathrm{O}_{2}$ catalyzed by $\mathrm{C}$ (under conditions of run 3, Table 1).

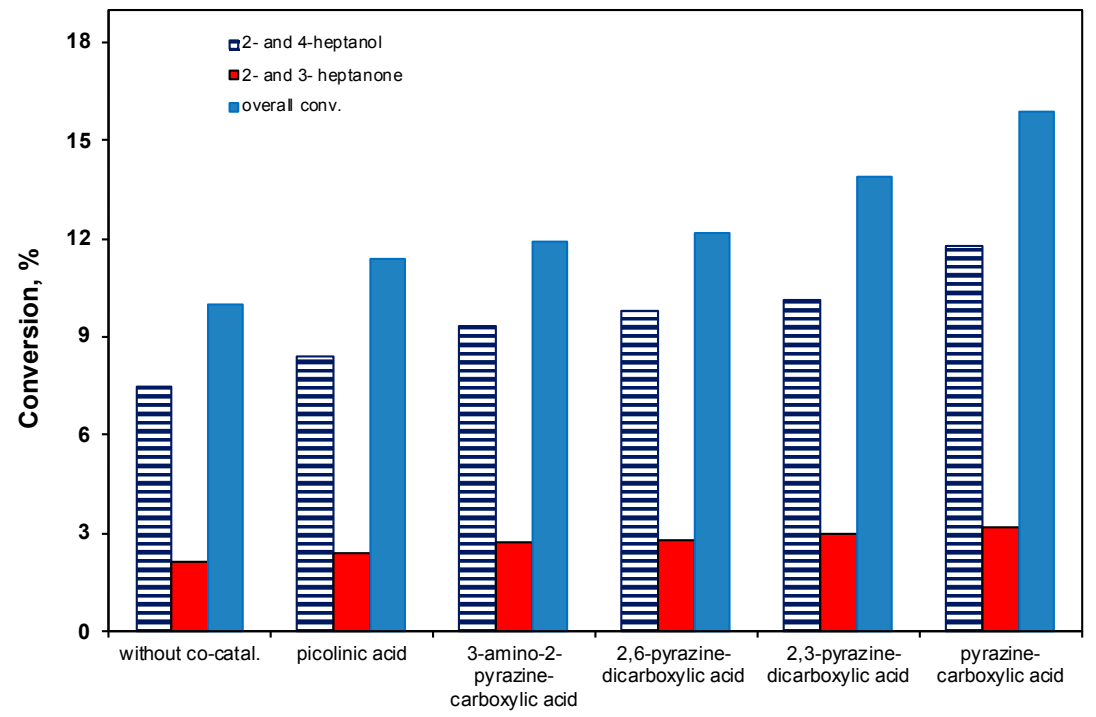

Figure 12. Effect of hetero-aromatic carboxylic acids (as co-catalysts) on conversion of $n$-heptane oxidation with $\mathrm{O}_{2}$ catalyzed by $\mathrm{C}$ (under conditions of run 7 , Table 1).

The promoting effect of an acid co-catalyst was already observed for other systems in the oxidative transformation of alkanes $[7,8,18,34-40]$ and conceivably consists of assisting proton transfer from a ligated $\mathrm{H}_{2} \mathrm{O}_{2}$ to an oxido-ligand via the carboxylate group of the pyrazinecarboxylate ligand, as suggested for homogeneous catalyst systems [41].

\subsection{Catalyst Stability and Recyclability}

The used catalyst $\mathbf{C}$ (runs 3 and 7, Table 1) was selected for the recycling studies. After the first essay, the reactor was degassed. $\mathrm{O}_{2}$ was then admitted (12 and $10 \mathrm{~atm}$, for hexane and heptane, respectively) and the reaction was left to proceed (2nd cycle) for a further $8 \mathrm{~h}$ reaction period. The overall conversions of $n$-hexane and $n$-heptane increased relative to the first cycle, from $12.6 \%$ to $14.8 \%$ and from $10.0 \%$ to $12.5 \%$, respectively, thus showing that the catalyst lost most of its initial activity.

For additional reuse essays, the supported catalyst $\mathrm{C}$, after being used in a cycle of $8 \mathrm{~h}$ under the above typical (for $n$-hexane and $n$-heptane oxidation) conditions, was reactivated by heating (see 
Section 3) and used for a second catalytic run with fresh reagents under the conditions of runs 3 and 7 of Table 1, for a duration of $16 \mathrm{~h}$. Then, the supported catalysts were separated from the reaction mixtures by filtration, carefully washed, and analysed for Re content. AAS analyses showed that the fresh catalyst $\mathrm{C}$ had $0.29 \pm 0.02 \%$ weight of Re metal content. After being used in the first cycle (for $8 \mathrm{~h}$ ), the Re content has decreased to $0.24 \pm 0.02 \%$ and $0.22 \pm 0.02 \%$ weight for the cases of $n$-hexane and $n$-heptane oxidation, respectively. In the second cycle (after $16 \mathrm{~h}$ ), only a negligible or minor loss of metal was observed, i.e., the Re content was $0.22 \pm 0.02 \%$ weight for $n$-hexane and $0.21 \pm 0.02 \%$ weight for $n$-heptane essays. After the second cycle, the overall conversions of $n$-hexane and $n$-heptane were $8.7 \%$ and $7.3 \%$, respectively, confirming the loss of activity of the catalyst. As the Re leaching was insignificant, the inactivation of the catalyst could involve the formation of $\mathrm{Re}=\mathrm{O}$ species over a long period under such an oxidative atmosphere, on account of the known affinity with Re by oxygenated species [29,31].

\subsection{Proposed Reaction Mechanism for n-Alkanes Oxidation}

Additional experiments under the same conditions as runs 3 and 7 of Table 1 were carried out in the presence of the carbon-radical trap bromotrichloromethane $\left(\mathrm{CBrCl}_{3}\right)$ or of the oxygen-radical trap diphenylamine $\left(\mathrm{Ph}_{2} \mathrm{NH}\right)$. The overall conversion dropped significantly for both $n$-alkanes. Consequently, we assume that the oxidation of the $n$-alkanes can proceed via a radical mechanism $[7,8,18,35-40]$. Free alkyl radicals $\left(\mathrm{R}^{\bullet}\right)$ could be obtained by reaction of the alkane $(\mathrm{RH})$ with $\mathrm{O}_{2}$ upon homolytic cleavage of a $\mathrm{C}-\mathrm{H}$ bond (slow reaction). Reaction of free alkyl $\mathrm{R}^{\bullet}$ with di-oxygen would form the alkylperoxy radical $\mathrm{ROO}^{\bullet}$, which could undergo metal-assisted decomposition to the alkoxyl radical $\mathrm{RO}^{\bullet}$. The alcohol $(\mathrm{R}-\mathrm{OH})$ could be formed either by $\mathrm{H}$-abstraction from the alkane (RH) by $\mathrm{RO}^{\bullet}$ or by Re-promoted decomposition of $\mathrm{ROO}^{\bullet}$ to yield also the ketone $\mathrm{R}(-\mathrm{H})=\mathrm{O}$.

The co-catalyst (PCA) could assist in these metal-induced $\mathrm{ROOH}$ cleavage reactions by promoting proton transfer from the $\mathrm{ROOH}$ ligand to an oxido (or hydroxido) ligand, to form the coordinated alkylperoxido (ROO) species subject to bond cleavage as proposed $[6,40,42,43]$ for oxido-vanadium $/ \mathrm{H}_{2} \mathrm{O}_{2}$ systems.

The presence of alkyl hydroperoxides was detected by gas chromatography using the well-known Shul'pin's method [42,43]. Additional gas chromatographic (GC) injections of the samples after treatment with triphenylphosphine were performed to ensure the precise quantification of the oxidation products present in the reaction solution, as alkyl hydroperoxides can be converted quantitatively to the corresponding alcohols by reduction with triphenylphosphine. In fact, when the triphenylphosphine was added to a sample (from the reaction at the optimized conditions) prior to the GC analysis a significant increase of ca. $30 \%$ of the alcohols obtained was observed for both substrates ( $n$-hexane and $n$-heptane), indicating that the alkyl hydroperoxide is formed as the primary product.

\section{Materials and Methods}

Complexes $\left[\mathrm{ReCl}_{2}\left\{\mathrm{NNC}(\mathrm{O}) \mathrm{C}_{6} \mathrm{H}_{5}\right\}(\mathrm{Hpz})\left(\mathrm{PPh}_{3}\right)_{2}\right]$ (A) (where $\mathrm{Hpz}$ is pyrazole), $\left[\mathrm{ReCl}_{2}\left\{\mathrm{NNC}(\mathrm{O}) \mathrm{C}_{6} \mathrm{H}_{5}\right\}(\mathrm{Hpz})_{2}\left(\mathrm{PPh}_{3}\right)\right]$ (B) [29], [ReClF $\left.\left\{\mathrm{NNC}(\mathrm{O}) \mathrm{C}_{6} \mathrm{H}_{5}\right\}(\mathrm{Hpz})_{2}\left(\mathrm{PPh}_{3}\right)\right]$ (C) [17], and $\left[\mathrm{ReOCl}_{3}\left(\mathrm{PPh}_{3}\right)_{2}\right]$ (D) [31] (Scheme 1) were prepared according to previous published methods, under an $\mathrm{N}_{2}$ atmosphere using standard Schlenk techniques.

A silica surface was modified by the reaction of $20 \mu \mathrm{L}$ of 3-aminopropyl trimethoxysilane, $\mathrm{NH}_{2}\left(\mathrm{CH}_{2}\right)_{3} \mathrm{Si}\left(\mathrm{OCH}_{3}\right)_{3}$ with $400 \mathrm{mg}$ of silica gel (200-400 mash size) in $25 \mathrm{~mL}$ of toluene in a round-bottom flask. This mixture was refluxed overnight. The $\mathrm{NH}_{2}$-functionalized silica was separated from the solution and washed with deionized water in order to remove unanchored amino-silane species.

The prepared 3-aminopropyl-modified silica gel was used for anchoring the above Re complexes (Scheme 2). Each of the Re complexes A-D (25 mg) was separately dissolved in methanol (10 mL); the solution was then added to the 3-aminopropyl-modified silica $(1.00 \mathrm{~g})$ and the mixture was refluxed for $5 \mathrm{~h}$ in the presence of $\mathrm{K}_{2} \mathrm{CO}_{3}$ and methanol. Hybrid Re catalysts were separated by filtration, washed 
several times with methanol, dried at $40{ }^{\circ} \mathrm{C}$ for $6 \mathrm{~h}$ under nitrogen, and then at $50{ }^{\circ} \mathrm{C}$ for $4 \mathrm{~h}$ in an oven. Quantities of $21 \mathrm{mg}$ of $\left[\mathrm{ReCl}_{2}\left\{\mathrm{~N}_{2} \mathrm{C}(\mathrm{O}) \mathrm{Ph}\right\}(\mathrm{Hpz})\left(\mathrm{PPh}_{3}\right)_{2}\right] \mathrm{A}, 20 \mathrm{mg}$ of $\left[\mathrm{ReCl}_{2}\left\{\mathrm{~N}_{2} \mathrm{C}(\mathrm{O}) \mathrm{Ph}\right\}(\mathrm{Hpz})_{2}\left(\mathrm{PPh}_{3}\right)\right]$ B, $23 \mathrm{mg}$ of $\left[\mathrm{ReClF}\left\{\mathrm{N}_{2} \mathrm{C}(\mathrm{O}) \mathrm{C}_{6} \mathrm{H}_{5}\right\}(\mathrm{Hpz})_{2}\left(\mathrm{PPh}_{3}\right)\right] \mathbf{C}$, and $19 \mathrm{mg}$ of $\left[\mathrm{ReOCl}_{3}\left(\mathrm{PPh}_{3}\right)_{2}\right]$ D were loaded per gram of 3-aminopropyl-functionalized silica support. The colors of the hybrid materials are as follows: yellow for $\mathbf{A}-\mathbf{C}$ and light green for $\mathbf{D}$.

Far-infrared spectra FIR $\left(400-200 \mathrm{~cm}^{-1}\right)$ of supported A-D were recorded on a Vertex 70 spectrophotometer in CsI pellets (Bruker, Bremen, Germany).

The morphology of the prepared hybrid materials was examined by Scanning Electron Microscopy (SEM) on a FEI Quanta 400 (JEOL, Tokyo, Japan)., and energy-dispersive EDS studies were also performed in the same analysis. The $\mathrm{C}, \mathrm{H}, \mathrm{N}$ elemental analyses were carried out by the Micro-Analytical Service at Instituto Superior Técnico (IST). TGA of the catalysts were performed using a Setaram TG/DTA/DSC-92 instrument (Setaram Instrumentation, Caluire, France).

All the oxidation reactions were conducted in a cylindrical-shaped SS pressure reactor $(18 \mathrm{~mL}$ capacity). Internal temperature and pressure of the reactor were monitored by a thermocouple and a pressure gauge, respectively. In typical oxygenation reaction conditions, $3.0 \mathrm{~mL}$ of neat $n$-alkane and the supported Re catalyst were added to the reactor where molecular $\mathrm{O}_{2}$ was introduced. The system was heated to the desired temperature. After reaction, the solid catalyst was separated from the liquid product by filtration, washed several times with acetonitrile and dried at $60^{\circ} \mathrm{C}$ overnight. The dried used catalyst was collected for further recycling studies. The color of the used catalyst turned into light brown.

The formed products were quantitatively analysed by gas chromatography (GC) in a FISONS Instruments GC 8000 series gas chromatograph (Jasco, Tokyo, Japan) equipped with a FID detector and a DB-WAX capillary column (length: $30 \mathrm{~m}$; internal diameter: $0.32 \mathrm{~mm}$ ) using helium as a carrier gas and 2-pentanone as internal standard (added to a $1 \mathrm{~mL}$ sample). The products were identified, and their retention times confirmed with those of commercially available (Aldrich) samples. The product peaks were further confirmed in a GC-MS Carlo Erba Instruments Auto/HRGC/MS (Jasco, Tokyo, Japan) with a DB-Wax column. Reaction products were identified by comparison of their mass spectra to fragmentation patterns obtained from the NIST spectral library stored in the computer software of the mass spectrometer.

TONs (turnover numbers) were calculated as the number of moles of products per mole of Re complex supported on silica and the yield values were calculated as moles of the desired product per mole of substrate. The selectivity was calculated as moles of product per mole of total yield of all products [17].

\section{Conclusions}

We have successfully used four 3-aminopropyl silica-supported Re complex catalysts (A-D) for the industrially important oxidation of $n$-alkanes by molecular oxygen (an ideal "green" oxidant) to obtain valuable oxidized products. Among them, the fluoro-containing $\left[\operatorname{ReClF}\left\{\mathrm{NNC}(\mathrm{O}) \mathrm{C}_{6} \mathrm{H}_{5}\right\}(\mathrm{Hpz})_{2}\left(\mathrm{PPh}_{3}\right)\right]$ (C) catalyst achieved the highest TONs up to $3.8 \times 10^{3}$ and $2.5 \times 10^{3}$, overall conversion of $12.6 \%$ and $10 \%$, and selectivity of $84.9 \%$ (2- and 3-hexanol and 2-hexanone) and $96.0 \%$ (2- and 4-heptanol, 2- and 3-heptanone) for $\mathrm{C}_{6}$ and $\mathrm{C}_{7}$-alkanes, respectively. Among the main oxidation products, the best selectivities were attained for 2-hexanol (40.5\%) and 4-heptanol (54.7\%), after $8 \mathrm{~h}$ at $p\left(\mathrm{O}_{2}\right)=12$ or $10 \mathrm{~atm}$ and at 150 or $160^{\circ} \mathrm{C}$, for $n$-hexane and $n$-heptane, respectively. TGA results indicate that catalysts A-D are stable at the applied temperature range $\left(100-200{ }^{\circ} \mathrm{C}\right)$; however, recycled $\mathbf{C}$ is much less active in subsequent catalytic cycles, suggesting its deactivation under the oxidative reaction conditions. Tests with both $\mathrm{C}$ - and O-centered radical traps indicate that the products are formed through free-radical reactions. 
Supplementary Materials: Supplementary materials are available online at www.mdpi.com/2073-4344/8/3/114/s1. Figure S1: (a1) Exemplary GC-MS chromatogram from the $n$-hexane oxidation with $\mathrm{O}_{2}$ catalyzed by $\mathrm{C}\left[p\left(\mathrm{O}_{2}\right)=12\right.$ atm, $8 \mathrm{~h}$ ]; internal standard: 2-pentanone; (a2) integrated chromatogram; (b) fragmentation patterns of selected retention times, obtained from the NIST spectral library stored in the computer software of the mass spectrometer); Figure S2: (a) Exemplary GC-MS chromatogram from the $n$-heptane oxidation with $\mathrm{O}_{2}$ catalyzed by $\mathbf{C}\left[p\left(\mathrm{O}_{2}\right)=10\right.$ atm, $8 \mathrm{~h}$ ]; internal standard: 2-pentanone; (b) fragmentation patterns of selected retention times, obtained from the NIST spectral library stored in the computer software of the mass spectrometer.

Acknowledgments: Financial support from the Fundação para a Ciência e a Tecnologia (FCT), Portugal, for the PTDC/QEQ-ERQ/1648/2014, PTDC/QEQ-QIN/3967/2014, and UID/QUI/00100/2013 projects are gratefully acknowledged. G.S.M. is also thankful to FCT, Portugal, for the "Indian-Portuguese Cooperation Program 2013" project (FCT/9701/25/10/2013/S).

Author Contributions: G.S.M., E.C.B.A.A. and L.M.D.R.S.M. conceived and designed the experiments; G.S.M., E.C.B.A.A. and L.M.D.R.S.M. performed the experiments and analyzed the data; L.M.D.R.S.M. and A.J.L.P. provided the means needed for the realization of this work. All the authors contributed to the writing, reading, and approval of the manuscript.

Conflicts of Interest: The authors declare no conflict of interest.

\section{References}

1. Hodnett, B.K. Heterogeneous Catalytic Oxidation: Fundamental and Technological Aspects of the Selective and Total Oxidation of Organic Compounds; John Wiley \& Sons: New York, NY, USA, 2000.

2. Centi, G.; Cavani, F.; Trifiro, F. Selective Oxidation by Heterogeneous Catalysis; Kluwer Academic/Plenum Publishers: New York, NY, USA, 2001.

3. Kroschwitz, J.I. Kirk-Othmer Encyclopedia of Chemical Technology; John Wiley \& Sons: New York, NY, USA, 2014.

4. Ullmann's Encyclopedia of Industrial Chemistry, 6th ed.; Wiley-VCH: Weinheim, Germany, 1999-2016; Volume 11, pp. 41-49.

5. Clerici, M.G.; Ricci, M.; Strukul, G. Metal-Catalysis in Industrial Organic Processes; Chiusoli, G.P., Maitlis, P.M., Eds.; Royal Society of Chemistry: Cambridge, UK, 2006.

6. Martins, L.M.D.R.S. C-homoscorpionate oxidation catalysts-Electrochemical and catalytic activity. Catalysts 2017, 7, 12. [CrossRef]

7. Martins, L.M.D.R.S.; Pombeiro, A.J.L. Water-soluble C-scorpionate complexes: Catalytic and biological applications. Eur. J. Inorg. Chem. 2016, 15-16, 2236-2252. [CrossRef]

8. Silva, T.F.S.; Mishra, G.S.; da Silva, M.F.G.; Wanke, R.; Martins, L.M.D.R.S.; Pombeiro, A.J.L. CuII complexes bearing the 2,2,2-tris(1-pyrazolyl)ethanol or 2,2,2-tris(1-pyrazolyl)ethylmethanesulfonate scorpionates. X-Ray structural characterization and application in the mild catalytic peroxidative oxidation of cyclohexane. Dalton Trans. 2009, 42, 9207-9215. [CrossRef] [PubMed]

9. Kuznetsov, M.L.; Kozlov, Y.N.; Mandelli, D.; Pombeiro, A.J.L.; Shul'pin, G.B. Mechanism of Al ${ }^{3+}$ _Catalyzed Oxidations of Hydrocarbons: Dramatic Activation of $\mathrm{H}_{2} \mathrm{O}_{2}$ toward $\mathrm{O}-\mathrm{O}$ Homolysis in Complex $\left[\mathrm{Al}\left(\mathrm{H}_{2} \mathrm{O}\right)_{4}(\mathrm{OOH})\left(\mathrm{H}_{2} \mathrm{O}_{2}\right)\right]^{2+}$ Explains the Formation of $\mathrm{HO} \bullet$ Radicals. Inorg. Chem. 2011, 50, 3996-4005. [CrossRef] [PubMed]

10. Bäckwall, J.-E. Modern Oxidation Methods; Wiley-VCH: Weinheim, Germany, 2004.

11. Olah, G.A.; Molnar, A. Hydrocarbon Chemistry, 3rd ed.; Wiley: New York, NY, USA, 1995; p. 10.

12. Yasutaka, I.; Sakaguchi, S.; Iwahama, T. Innovation of Hydrocarbon oxidation with molecular oxygen and related reactions. Adv. Synth. Catal. 2001, 243, 393-427. [CrossRef]

13. Mishra, G.S.; Kumar, A. Silica gel supported [1,4-bis(salicylidene amino)-phenylene] vanadium oxo complex catalyst for the oxidation of n-heptane using molecular oxygen. J. Mol. Catal. A Chem. 2003, 192, $275-280$. [CrossRef]

14. Pérez, P.J. (Ed.) Alkane C-H Activation by Single Site Metal Catalysts; Springer: Berlin/Heidelberg, Germany, 2012; p. 143.

15. Machado, K.; Mishra, J.; Suzuki, S.; Mishra, G.S. Synthesis of superparamagnetic carbon nanotubes immobilized $\mathrm{Pt}$ and $\mathrm{Pd}$ pincer complexes: Highly active and selective catalysts towards cyclohexane oxidation with dioxygen. Dalton Trans. 2014, 43, 17475-17482. [CrossRef] [PubMed]

16. Machado, K.; Tavares, P.B.; Mishra, G.S. Synthesis and application of $\mathrm{Fe}^{\mathrm{III}}, \mathrm{Ni}^{\mathrm{II}}$ and $\mathrm{Mn}^{\mathrm{II}}$ complexes anchored to HMS as efficient catalysts for cycloalkane oxyfunctionalization. J. Mol. Catal. A Chem. 2014, 383-384, 159-166. [CrossRef] 
17. Mishra, G.S.; Alegria, E.C.B.; Martins, L.M.D.R.S.; Fraústo da Silva, J.J.R.; Pombeiro, A.J.L. Cyclohexane oxidation with dioxygen catalyzed by supported pyrazole rhenium complexes. J. Mol. Catal. A Chem. 2008, 285, 92-100. [CrossRef]

18. Martins, L.M.D.R.S.; Pombeiro, A.J.L. Tris(pyrazol-1yl)methane metal complexes for catalytic mild oxidative functionalizations of alkanes, alkenes and ketones. Coord. Chem. Rev. 2014, 265, 74-88. [CrossRef]

19. Anisia, K.S.; Kumar, A. Oxidation of n-heptane with molecular oxygen using heterogeneous catalyst formed by covalently binding [1,2-bis(salicylideneamino)-phenylene] zirconium complex to modified silica gel. J. Mol. Catal. A Chem. 2004, 219, 319-326. [CrossRef]

20. Machado, K.; Freire, C.; Kumar, A.; Tavares, P.B.; Mishra, G.S. Single site anchored novel pentacoordinate Schiff-base $\mathrm{Co}^{\mathrm{II}}$ complexes over SBA-15 for selective oxidation $\left(\mathrm{O}_{2}\right)$ of n-alkanes and kinetic study. Polyhedron 2014, 69, 119-126. [CrossRef]

21. Stekrova, M.; Zdenkova, R.; Vesely, M.; Vyskocilova, E.; Cerveny, L. Immobilization of methyltrioxorhenium on mesoporous aluminosilicate materials. Materials 2014, 7, 2650-2668. [CrossRef] [PubMed]

22. O'Connor, R.P.; Schmidt, L.D. $C_{6}$ oxygenates from n-hexane in a single-gauze reactor. Chem. Eng. Sci. 2000, 55, 5693-5703. [CrossRef]

23. Zhan, B.-Z.; Modén, B.; Dakka, J.; Santiesteban, J.G.; Iglesia, E. Catalytic oxidation of n-hexane on Mn-exchanged zeolites: Turnover rates, regioselectivity, and spatial constraints. J. Catal. 2007, 245, 316-325. [CrossRef]

24. Stoylkova, T.Y.; Chanev, C.D.; Lechert, H.T.; Bezouhanova, C.P. Oxidative conversion of n-heptane over molecular sieves. Appl. Catal. A Gen. 2000, 203, 121-126. [CrossRef]

25. Mishra, G.S.; Machado, K.; Kumar, A. Highly selective n-alkanes oxidation to ketones with molecular oxygen catalyzed by SBA-15 supported rhenium catalysts. J. Ind. Eng. Chem. 2014, 20, 2228-2235. [CrossRef]

26. Mishra, G.S.; Pombeiro, A.J.L. Oxyfunctionalization of n-pentane and n-hexane by oxovanadium complexes supported on carbamated modified silica gel. Appl. Catal. A Gen. 2006, 304, 185-194. [CrossRef]

27. Mishra, G.S.; Kumar, A. Selective oxidation of linear alkanes by Schiff base ligand 1,4-bis(salicylidene amino)-phenylene vanadium complex bonded on modified silica gel. Kinet. Catal. 2004, 45, 394-399. [CrossRef]

28. Alegria, E.C.B.; Martins, L.M.D.R.S.; Haukka, M.; Pombeiro, A.J.L. Rhenium Complexes of Tris(pyrazolyl)methanes and Sulfonate Derivative. Dalton Trans. 2006, 4954-4961. [CrossRef] [PubMed]

29. Alegria, E.C.B.A.; Martins, L.M.D.R.S.; Guedes da Silva, M.F.C.; Pombeiro, A.J.L. Syntheses and Properties of Re(III) Complexes Derived from Hydrotris(1-pyrazolyl)methanes. Molecular Structure of $\left[\mathrm{ReCl}_{2}\left(\mathrm{HCpz}_{3}\right)\left(\mathrm{PPh}_{3}\right)\right]\left[\mathrm{BF}_{4}\right]$. J. Organomet. Chem. 2005, 690, 1947-1958. [CrossRef]

30. Martins, L.M.D.R.S.; Alegria, E.C.B.A.; Smoleński, P.; Kuznetsov, M.L.; Pombeiro, A.J.L. Oxorhenium complexes bearing the water-soluble tris(pyrazol-1-yl)methanesulfonate, 1,3,5-triaza-7-phosphaadamantane or related ligands, as catalysts for the Baeyer-Villiger oxidation of ketones. Inorg. Chem. 2013, 52, 4534-4546. [CrossRef] [PubMed]

31. Parshall, G.W.; Shive, L.W.; Cotton, F.A. Inorganic Syntheses; John Wiley \& Sons: New York, NY, USA, 1977; Volume 17, pp. 110-112. [CrossRef]

32. Alegria, E.C.B.; Kirillova, M.V.; Martins, L.M.D.R.S.; Pombeiro, A.J.L. Pyrazole and trispyrazolylmethane rhenium complexes as catalysts for ethane and cyclohexane oxidations. Appl. Catal. A Gen. 2007, 317, 43-52. [CrossRef]

33. Pombeiro, A.J.L. Characterization of Coordination Compounds by Electrochemical Parameters. Eur. J. Inorg. Chem. 2007, 1473-1482. [CrossRef]

34. Martins, L.M.D.R.S.; Martins, A.; Alegria, E.C.B.A.; Carvalho, A.P.; Pombeiro, A.J.L. Efficient cyclohexane oxidation with hydrogen peroxide catalysed by a C-scorpionate iron(II) complex immobilized on desilicated MOR zeolite. Appl. Catal. A 2013, 464-465, 43-50. [CrossRef]

35. Milunovic, M.N.M.; Martins, L.M.D.R.S.; Alegria, E.C.B.A.; Pombeiro, A.J.L.; Krachler, R.; Trettenhahn, G.; Turta, C.; Shova, S.; Arion, V.B. Hexanuclear and undecanuclear iron(III) carboxylates as catalyst precursors for cyclohexane oxidation. Dalton Trans. 2013, 42, 14388-14401. [CrossRef] [PubMed]

36. Martins, L.M.D.R.S.; de Peixoto Almeida, M.; Carabineiro, S.A.C.; Figueiredo, J.L.; Pombeiro, A.J.L. Heterogenisation of a C-scorpionate Fe(II) complex in carbon materials for cyclohexane oxidation with hydrogen peroxide. Chem CatChem 2013, 5, 3847-3856. [CrossRef] 
37. Sutradhar, M.; Martins, L.M.D.R.S.; Guedes da Silva, M.F.C.; Pombeiro, A.J.L. Vanadium complexes: Recent progress in oxidation catalysis. Coord. Chem. Rev. 2015, 301-302, 200-239. [CrossRef]

38. Kuznetsov, M.L.; Pombeiro, A.J.L. Radical formation in the $\left[\mathrm{MeReO}_{3}\right]$-catalyzed aqueous peroxidative oxidation of alkanes: A theoretical mechanistic study. Inorg. Chem. 2009, 48, 307-318. [CrossRef] [PubMed]

39. Shul'pin, G.B. C-H functionalization: Thoroughly tuning ligands at a metal ion, a chemist can greatly enhance catalyst's activity and selectivity. Dalton Trans. 2013, 42, 12794-12818. [CrossRef] [PubMed]

40. Silva, T.F.S.; Luzyanin, K.V.; Kirilova, M.V.; Silva, M.F.C.G.; Martins, L.M.D.R.S.; Pombeiro, A.J.L. Novel scorpionate and pyrazole dioxovanadium complexes, catalysts for carboxylation and peroxidative oxidation of alkanes. Adv. Synth. Catal. 2010, 352, 171-187. [CrossRef]

41. Shul'pin, G.B.; Kozlov, Y.N.; Nizova, G.V.; Süss-Fink, G.; Stanislas, S.; Kitaygorodskiy, A.; Kulikova, V.S. Oxidations by the reagent " $\mathrm{O}_{2}-\mathrm{H}_{2} \mathrm{O}_{2}$-vanadium derivative-pyrazine-2-carboxylic acid". Part 12.1 Main features, kinetics and mechanism of alkane hydroperoxidation. J. Chem. Soc. Perkin Trans. 2001, 2, 1351-1371.

42. Shul'pin, G.B.; Kozlov, Y.N.; Shul'pina, L.S.; Kudinov, A.R.; Mandelli, D. Extremely Efficient Alkane Oxidation by a New Catalytic Reagent $\mathrm{H}_{2} \mathrm{O}_{2} / \mathrm{Os}_{3}(\mathrm{CO})_{12}$ /Pyridine. Inorg. Chem. 2009, 48, 10480-10482. [CrossRef]

43. Shul'pin, G.B.; Kozlov, Y.N.; Shul'pina, L.S.; Petrovskiy, P.V. Oxidation of alkanes and alcohols with hydrogen peroxide catalyzed by complex $\mathrm{Os}_{3}(\mathrm{CO})_{10}(\mu-\mathrm{H})_{2}$. Appl. Organomet. Chem. 2010, 24, 464-472. [CrossRef]

(c) 2018 by the authors. Licensee MDPI, Basel, Switzerland. This article is an open access article distributed under the terms and conditions of the Creative Commons Attribution (CC BY) license (http:/ / creativecommons.org/licenses/by/4.0/). 